\title{
Does Latent Strabismus Affect Stereoacuity?
}

\author{
(D) Feray Koç ${ }^{1}$, (D) Berkay Akmaz², (D) Nazife Sefi Yurdakul ${ }^{3}$ \\ ${ }^{1}$ Katip Çelebi University Atatürk Training and Research Hospital, Clinic of Ophthalmology, Izmir, Turkey \\ 2 Manisa City Hospital, Clinic of Ophthalmology, Manisa, Turkey \\ ${ }^{3}$ Başkent University Zübeyde Hanım Hospital, Clinic of Ophthalmology, Izmir, Turkey
}

\section{Abstract}

Objective: The purpose of this study is to determine the effect of latent strabismus on stereoacuity.

Methods: Stereoacuities of normal individuals, ranging in age from 18 to 35 years, were measured using the TNO or Titmus tests. The study population was divided into 2 groups regarding the achievement of the accepted excellent stereoacuity threshold of 30 arcseconds (group A) or not (group B). The relationship between latent deviation angles and stereoacuity levels were evaluated.

Results: Latent deviation angles ranged from 0 to 35 prism diopters (PD). Both TNO ( $r=0.380 p=0.002)$ and Titmus ( $r=0.306 p=0.015)$ stereothresholds tended to increase as the latent deviation angles increased. Group A included 27 participants who had either exophoria (18) or orthophoria (9), and the mean deviation angle of this group was 3.07 \pm 3.26 PD. Group B included 36 participants, 28 of whom had exophoria, three had esophoria, and the remaining five had orthophoria. The mean angle of deviation in group B was 6.50 \pm 6.92 PD. This value was statistically higher than the mean deviation angle in group $A(p=0.012)$. Though none of the esophoric participants achieved excellent stereoacuity, the distribution of the deviation types did not cause any difference between the groups $(p=0.077)$. The mean age of group A was found to be higher than that of group B ( $p=0.006)$.

Conclusion: Latent deviation can mask true stereosensitivity potentials of subjects to some extent during the stereotesting procedure.

Keywords: Stereopsis, latent deviation, TNO test, Titmus test

\section{INTRODUCTION}

Stereopsis is defined as the relative ordering of visual objects in depth. The differences between the locations of matching features on the retinas are termed binocular disparities, and the ability to perceive depth from these disparities is stereopsis (1). A normal level of disparity arises from the viewing of fixation point by both eyes with several minutes of the arc of angle difference (2). However, disparity might increase in cases of a monocular blur, ocular misalignment, and aniseikonia $(3,4)$. High-grade stereopsis requires bi-foveal fixation, precise motor control of eyes, and bilateral high-level visual acuities as prerequisites $(2,3,5)$. However, subjects with unexpectedly lowlevel stereoacuities can be seen, despite orthotropia and normal bilateral vision. Several explanations might account for this condition. Disparity-selective V1 neurons in the striate cortex of these subjects may be incapable of perceiving minor disparities that result in fine stereopsis (1). The false-negativity related to the stereotests used might be another explanation since the stereoacuities obtained in stereograms using targets with and without detectable monocular contours might differ quite a great deal $(4,6-8)$. Stereotests are applied while the eyes are in dissociated conditions, and the manifestation of latent deviations during the procedure might prevent fusion and, consequently, stereopsis. It has been shown that microtropic subjects with a horizontal deviation exceeding 4-5 prism diopters (PD) were least likely to demonstrate stereopsis (9-12). However, these microtropic subjects usually have central suppression, besides microtropia, which might cause weak stereopsis. The effect of an

Phone: +90 5325255233 E-mail: dr_feray@yahoo.com ORCID ID: orcid.org/0000-0002-1003-3741

Cite this article as: Koç F, Akmaz B, Sefi Yurdakul N. Does Latent Strabismus Affect Stereoacuity? Eur Arch Med Res 2021;37(1):15-9

- Copyright 2021 by the University of Health Sciences Turkey, Prof. Dr. Cemil Taşçığlu City Hospital

European Archives of Medical Research published by Galenos Publishing House. 
isolated deviation on stereopsis can be determined by studying subjects with only latent deviation and no other anomaly, such as amblyopia, anisometropia, and strabismus history. This study aims to investigate whether latent deviation amplitudes affect measured stereoacuity levels using both contour-based (Titmus) and random-dot (TNO) stereograms in normal subjects.

\section{METHODS}

This prospective study was conducted with participants recruited from the hospital staff and medical faculty students. Informed consent was obtained from all individual participants included in the study. The study was performed in accordance with the tenets of the Declaration of Helsinki with the approval of the Institutional Review Board. Ethics Committee of Izmir Katip Çelebi University (decision number: 56, date: 06.02.2019).

All participants had full eye examinations, including bestcorrected visual acuities, biomicroscopic anterior segment, and fundus examinations. Spherical equivalents of refractive errors were recorded. Next, an alternate cover test was used to determine if any latent deviation for distant and near fixation was present. If there was a latent deviation, control of the deviation for distance and near fixation was evaluated. Subjects who had control of the deviation immediately after 10 seconds of monocular occlusion were included. Deviations were measured for near and distant fixations using the prismcover test. The Worth-4-Dot (W4D) test was used to evaluate fusion.

The criteria for inclusion in the research are given below.

1- Normal visual acuity in both eyes (at least 20/20 Snellen),

2- No prior history of amblyopia or amblyopia treatment,

3- No prior history of intermittent or manifest strabismus,

4- Anisometropia less than -1.00 diopter myopia or astigmatism and $<+0.50$ hypermetropia,

5- Fusion for distance and close in the W4D test, and

6- Age 18-35 years of old.

Stereoacuities were measured using both contour (Titmus test; Stereo Optical Co, Chicago, IL, USA) and random-dot (TNO test; 15th edition, Lameris Ootech BV) stereograms. The Titmus test uses contoured stimuli with polaroid glasses to separate the stimuli presented to each eye. Clues are presented that allow the circle with the disparity to be identified as different under monocular viewing conditions. The TNO test uses random-dot stimuli with red-green glasses to separate the images presented to each eye. There are no monocular clues that enable the identification of the stereotarget. Only the near stereoacuity thresholds were evaluated.

All participants had stereoacuity measurements in the same examining room and illumination conditions. The time required for each test was recorded. If the measured stereoacuity was above 60 arcseconds, stereosensitivity was retested with the same tests in the same circumstances to confirm the result. The lowest measurement was recorded if the measurements were not the same. Participants were divided into 2 groups, regarding the achievement of the excellent stereoacuity level (30 arcseconds) (13). Group A included participants who achieved 30 arcseconds stereoacuity, and group B included the others.

\section{Statistical Analyses}

The correlations between stereoacuity levels and latent deviation angles were tested using Pearson's correlation analysis. Either independent samples t-test or Mann-Whitney $U$ test was used to compare the continuous variables of group A and B after testing the equality of variances of the groups with the Levene's test. The categorical variables of the groups were compared using the Pearson chi-square test. A $p$ value of $<0.05$ was considered statistically significant.

\section{RESULTS}

Of the 63 individuals who met the criteria, 45 were female. The mean age was $27.04 \pm 5.32$ years. Absolute values of latent deviation angles ranged from 0 to $35 \mathrm{PD}$, with an average of $5.03 \pm 5.86 \mathrm{PD}$. The stereosensitivity threshold values of the Titmus stereotest ranged from 40 to 160 arcseconds, and the stereosensitivity threshold values with the TNO test ranged from 15 to 480 arcseconds. The time required to perform the Titmus stereotest was 30-60 seconds. On the other hand, performing the TNO test required 3-5 minutes. Fifty-nine participants (92\%) showed 60 arcseconds or better stereosensitivity level at least in one of the tests, and fifty-five (87\%) participants showed this level in both tests.

The common feature of four participants who could not achieve normal stereosensitivity in both tests was that the near-deviation angles were higher than those in the distance. There was convergence insufficiency type exophoria in three participants, and the fourth participant had convergence excess type esophoria. In these four cases, the near-deviation angles were 6-12 PD higher than the distance angles. Similar convergence-divergence imbalances were observed in three of the four participants, who achieved normal level stereoacuity in 
only the Titmus test. The fourth case in this subgroup had the highest deviation (35 PD) of the study group for both near and distance fixations. Another common feature of these cases was their variable stereosensitivity thresholds detected on retesting to confirm their abnormally high stereosensitivity thresholds.

There was a significant correlation between the Titmus and TNO tests $(r=0.802, p<0.001)$. However, as the near-deviation angles increased, stereosensitivity thresholds also increased in both tests but reached statistical significance at different levels (TNO, $p<0.01$; Titmus, $p<0.05$ ) (Table 1). Twenty-seven participants who achieved the perfect stereosensitivity level were grouped in group $A$, and the rest of the participants who had lower stereosensitivity were grouped in group B.

Comparisons of the group parameters are given in Table 2. Groups were similar in terms of gender distribution and refractive errors. While the mean age was significantly higher in group $A(p=0.006)$, the distant and near-deviation angles were significantly lower compared with group B. P values were 0.033 for the distant deviation angles and 0.012 for the neardeviation angles. Fourteen participants had a zero deviation angle on the prism-cover test, and $64 \%$ of these achieved an excellent stereoacuity level. The remaining 49 participants had

\begin{tabular}{|l|l|l|l|l|}
\hline \multicolumn{3}{|l|}{$\begin{array}{l}\text { Table 1. Correlation between deviation angles and stereotest } \\
\text { results }\end{array}$} \\
\hline Stereotests & Statistics & \multicolumn{3}{l|}{ Parameters } \\
\cline { 3 - 5 } & Age & $\begin{array}{l}\text { Near- } \\
\text { deviation } \\
\text { angle }\end{array}$ & $\begin{array}{l}\text { Distant } \\
\text { deviation } \\
\text { angle }\end{array}$ \\
\hline \multirow{3}{*}{ TNO } & $\begin{array}{l}\text { Pearson } \\
\text { correlation }\end{array}$ & -0.261 & 0.380 & 0.132 \\
\cline { 2 - 5 } & $p$ & 0.039 & 0.002 & 0.304 \\
\hline \multirow{3}{*}{ Titmus } & $\begin{array}{l}\text { Pearson } \\
\text { correlation }\end{array}$ & -0.214 & 0.306 & 0.029 \\
\cline { 2 - 5 } & $p$ & 0.920 & 0.015 & 0.824 \\
\hline
\end{tabular}

latent deviations that changed from 1 to 35 PD, and only 26\% of these achieved excellent stereoacuity. Latent deviation had a negative effect on the measured stereoacuity level, but how did the type of deviation affect the stereoacuity level? The deviation types were $67 \%$ exophoria and $33 \%$ orthophoria for group A, and $78 \%$ exophoria, $14 \%$ orthophoria, and 8\% esophoria for group B. Pearson chi-square analyses did not show a significant difference between the groups regarding the distribution of the deviation types $(p=0.077)$ (Table 2$)$.

\section{DISCUSSION}

Individuals with bi-foveal fixation typically have 60 arcseconds and lower stereosensitivity thresholds, whereas 30 arcseconds and below are defined as excellent levels of stereosensitivity (13). In this study, participants were grouped as having either excellent stereosensitivity or not, and the effect of latent deviation achieving on excellent level stereosensitivity was evaluated. Forty-four percent of the group achieved an excellent stereoacuity level. Both TNO and Titmus stereothresholds tended to increase significantly as the latent deviation angles increased. However, the correlation was stronger for the TNO test. These results indicate that the latent deviation angle has a significant effect on the measured stereosensitivity level. Additional support for this argument is the observed higher retesting variability in subjects with higher near latent deviations. The decompensation of phoria at different levels of each stereotesting might cause the variability measured on the stereosensitivity level. Fender and Julesz (14) studied Panum's fusional areas for randomdot stereograms and found that images stimulating both eyes must be aligned within 6 min arc disparity before fusion can occur. Though study participants had fusion for both distance and near on the W4D test, they might have lost their alignment and manifested latent deviations during the testing period of

Table 2. Comparison of the group with excellent stereosensitivity (group A) with the group who could not achieve excellent stereosensitivity (group B)

\begin{tabular}{|l|l|l|l|}
\hline Parameters & Group A $\mathbf{n = 2 7}$ & Group B $\mathbf{n = 3 6}$ & $\mathbf{p}$ \\
\hline Age (years) & $29.14 \pm 5.57$ & $25.47 \pm 4.60$ & 0.006 \\
\hline Sex (F/M) & $22 / 5$ & $23 / 13$ & 0.126 \\
\hline Refraction (diopter) & $-1.07 \pm 1.32$ & $-1.06 \pm 1.54$ & 0.395 \\
\hline Eso/exo/orthophoria (\%) & $0 / 67 / 33$ & $8 / 78 / 14$ & 0.077 \\
\hline Near-deviation (prism diopter) & $3.07 \pm 3.26$ & $6.50 \pm 6.92$ & 0.012 \\
\hline Distant deviation (prism diopter) & $2.51 \pm 3.06$ & $5.38 \pm 6.28$ & 0.033 \\
\hline TNO (arcseconds) & $24.44 \pm 7.38$ & $99.44 \pm 97.91$ & 0.000 \\
\hline Titmus (arcseconds) & $52.22 \pm 31.81$ & 0.089 \\
\hline F: Female, M: Male, Eso: Esophoria, Exo: Exophoria & & \\
\hline
\end{tabular}


stereopsis. Performing the W4D test takes a few seconds, but performing the TNO test takes 3-5 minutes and can lead to decompensated phoria.

Experimental studies investigating the effect of fusional stress on stereoacuity were done by simulating heterophoria using base-out prisms or Synoptophore. Laird et al. (15) observed degradation of stereoacuity as the convergence stress increased with base-out prisms. However, Tidbury et al. (16) did a similar study using Synoptophore instead of prisms and found no effect of convergence stress on stereoacuity if the phoria was well controlled. Both investigators compared baseline stereoacuities with the stereoacuities at the fusion recovery limits. The median fusion recovery limit was $20( \pm 4)$ PD for the Laird's group, whereas it was $8( \pm 6)$ PD for the Tidbury's group. Differences in their methodology might have caused the significantly different median fusion recovery limits and opposite results.

Archer et al. (17) evaluated vergence amplitudes with an amblyoscope using monocular and random-dot targets. They showed that random-dot stereograms could produce fusional vergence amplitudes once fusion had been obtained. They observed similar fusional vergence break-up amplitudes with random-dot and monocular targets. However, fusional recovery was more difficult or not possible for some subjects in randomdot targets. Similarly, subjects with latent deviations must recover fusion if their deviations are manifested during the stereotesting procedure; otherwise, no stereosensitivity can be measured.

Higher stereosensitivity thresholds up to 120 arcseconds were reported with the TNO test $(18,19)$. In this study, the mean stereosensitivity thresholds obtained with TNO and Titmus tests were $67( \pm 83)$ and $48( \pm 25)$ arcseconds, respectively. Despite full vision in both eyes, orthotropia, and fusion in the W4D test, four subjects had stereosensitivity thresholds over 60 arcseconds in both tests. The common feature of these subjects was the convergence-divergence imbalance for near fixation. The coupling of convergence-divergence imbalance with the disassociating effect of stereotesting might have led to the degradation of stereosensitivity thresholds. This condition corresponds to the diminished distant stereosensitivity thresholds in exophoric subjects who started to decompensate $(20,21)$.

An interesting result obtained in the study was that the group with an older average age showed improved stereosensitivity. The main explanation for this observation was this group's lower average deviation angle. Studies evaluating the effect of age on stereosensitivity report two different results: Age has no effect on stereosensitivity (22) and stereosensitivity decreases with age $(3,23,24)$. But most of these studies have evaluated only age groups over 60 years. Garnham and Sloper (23) evaluated stereosensitivity in normal subjects aged 1783 years and observed some decline in stereosensitivity with age by all tests. The decline started over 30 years of age for TNO and over 50 for the Titmus test. They also detected a small decline with age in the fusional divergence range for distance, but this change did not explain the stereosensitivity decline in their group. They suggested that the reduction found in these older subjects using a random-dot test might have been caused by an actual loss of stereosensitivity at the cortical level. The upper age range was 35 years in this study. There were 18 participants over 30 years of age, and most of them had stereosensitivities over the group average. Since all of them were ophthalmologists or ophthalmology residents, they might have shown an expert performance in the stereotests.

Another subject to be determined is the effect of deviation type on stereoacuity. As is known, divergence control mechanisms are stronger. In addition to the stronger fusional convergence amplitudes, accommodative, proximal, and tonic convergence mechanisms are also active at close fixation (25). Besides, whereas convergence is an active movement, divergence is passive, which occurs with the loosening of convergence (25). Decompensation of the exophoria could be compensated for by an innate convergence effort of the eyes to capture the fusible stereotarget. However, esophoria decompensation might be difficult to compensate for in the disassociated conditions of stereotesting. So, it might be expected that stereosensitivities of esophoric subjects are more fragile under disassociated conditions. None of the esophoric participants achieved an excellent level of stereoacuity in this study group. On the other hand, esophoria was a rare condition, and only $3(5 \%)$ of the participants were esophoric.

The weak point of this study is an inadequate representation of esophoric subjects in the group. Though we had some clues showing the negative effect of convergent latent deviation on stereoacuity, we could not prove it with significant power.

\section{CONCLUSION}

Our results demonstrated that latent deviation angles could mask true stereosensitivity potentials of subjects to some extent during the stereotesting procedure.

\section{Ethics}

Ethics Committee Approval: Ethics Committee of İzmir Katip Çelebi University (decision number: 56, date: 06.02.2019). 
Informed Consent: Informed consent was obtained from all individual participants included in the study.

Peer-review: Externally peer-reviewed.

\section{Authorship Contributions}

Surgical and Medical Practices: F.K., B.A., Concept: F.K., B.A., N.S.Y., Design: F.K., B.A., N.S.Y., Data Collection or Processing: F.K., B.A., N.S.Y., Analysis or Interpretation: F.K., B.A., Literature Search: F.K., Writing: F.K.

Conflict of Interest: No conflict of interest was declared by the authors.

Financial Disclosure: The authors declared that this study received no financial support.

\section{REFERENCES}

1. Cumming BG, DeAngelis GC. The physiology of stereopsis. Annu Rev Neurosci 2001;24:203-38.

2. Von Noorden GK, Campos EC. Binocular vision and space perception. In: Lampert R, Cox K, editors. Binocular Vision and Ocular Motility. 6th ed. Mosby: St. Louis; 1990.p.8-40.

3. Odell NV, Hatt SR, Leske DA, Adams WE, Holmes JM. The effect of induced monocular blur on measures of stereoacuity. J AAPOS 2009;13:136-41.

4. Leske DA, Birch EE, Holmes JM. Real depth vs randot stereotests. Am J Ophthalmol 2006;142:699-701.

5. Harwerth RS, Fredenburg PM. Binocular vision with primary microstrabismus. Invest Ophthalmol Vis Sci 2003;44:4293-306.

6. Frisby JP, Mein J, Saye A, Stanworth A. Use of random-dot sterograms in the clinical assessment of strabismic patients. $\mathrm{Br} J$ Ophthalmol 1975;59:545-52.

7. Lovasik JV, Szymkiw M. Effects of aniseikonia, anisometropia, accommodation, retinal illuminance, and pupil size on stereopsis. Invest Ophthalmol Vis Sci 1985;26:741-50.

8. Fu VL, Birch EE, Holmes JM. Assessment of a new Distance Randot stereoacuity test. J AAPOS 2006;10:419-23.

9. Rutstein RP, Eskridge JB. Stereopsis in small-angle strabismus. Am J Optom Physiol Opt 1984;61:491-8.

10. Lal G, Holmes JM. Postoperative stereoacuity following realignment for chronic acquired strabismus in adults. J AAPOS 2002;6:233-7.
11. Fawcett SL, Felius J, Stager DR. Predictive factors underlying the restoration of macular binocular vision in adults with acquired strabismus. J AAPOS 2004;8:439-44.

12. Fawcett SL, Stager DR Sr, Felius J. Factors influencing stereoacuity outcomes in adults with acquired strabismus. Am J Ophthalmol 2004;138:931-5.

13. Von Noorden GK, Campos EC. Depth Perception. In: Lampert R, Cox K, editors. Binocular Vision and Ocular Motility. 6th ed. Mosby: St. Louis; 2002.p.299-307.

14. Fender D, Julesz B. Extension of Panum's fusional area in binocularly stabilized vision. J Opt Soc Am 1967; 57:819-30.

15. Laird PW, Hatt SR, Leske DA, Holmes JM. Stereoacuity and binocular visual acuity in prism-induced exodeviation. J AAPOS 2007;11:362-6.

16. Tidbury LP, O'Connor AR, Wuerger SM. The effect of induced fusional demand on static and dynamic stereoacuity thresholds: the digital Synoptophore. BMC Ophthalmol 2019;19:6.

17. Archer SM, Miller KK, Helveston EM, Ellis FD. Vergence amplitudes with random-dot stereograms. Br J Ophthalmol 1986;70:718-23.

18. Vancleef K, Read JCA, Herbert W, Goodship N, Woodhouse M, SerranoPedraza I. Overestimation of stereo thresholds by the TNO stereotest is not due to global stereopsis. Ophthalmic Physiol Opt 2017;37:507-20.

19. Antona B, Barrio A, Sanchez I, Gonzalez E, Gonzalez G. Intraexaminer repeatability and agreement in stereoacuity measurements made in young adults. Int J Ophthalmol 2015;8:374-81.

20. Stathacopoulos RA, Rosenbaum AL, Zanoni D, Stager DR, McCall LC, Ziffer AJ, et al. Distance stereoacuity. Assessing control in intermittent exotropia. Ophthalmology 1993;100:495-500.

21. Holmes JM, Birch EE, Leske DA, Fu VL, Mohney BG. New tests of distance stereoacuity and their role in evaluating intermittent exotropia. Ophthalmology 2007;114:1215-20.

22. Yıldız AA, Bardak YK. Effects of age and Refractive Errors on Stereopsis Turk J Ophthalmol 2011;41:372-5.

23. Garnham L, Sloper JJ. Effect of age on adult stereoacuity as measured by different types of stereotest. Br J Ophthalmol 2006;90:91-5.

24. Zaroff CM, Knutelska M, Frumkes TE. Variation in stereoacuity: normative description, fixation disparity, and the roles of aging and gender. Invest Ophthalmol Vis Sci 2003;44:891-900.

25. Von Noorden GK, Campos EC. Physiology of the Ocular Movements. In: Lampert R, Cox K, editors. Binocular Vision and Ocular Motility. 6th ed. Mosby: St. Louis; 2002.p.52-84. 